\title{
Morphometric Analysis of the Human Trigeminal Nerve
}

\author{
By
Hiromitsu EZURE, Noboru GOTO, Naoko NONAKA, Jun GOTO and Hiroaki TANI

Department of Anatomy, Showa University School of Medicine, 5-8, Hatanodai 1. Shinagawa-ku, Tokyo 142-8555,
Japan

- Received for Publication, February 6, 2001 -

Key Words: Human, Trigeminal nerve, Motor root, Sensory root, Nerve fiber, Morphometry

\begin{abstract}
Summary: We evaluated the components of nerve fibers of the motor and sensory roots of the trigeminal nerve by morphometric analysis. Trigeminal nerves were obtained from 5 cadavers (males, aged 67-95) were stained by MassonGoldner-Goto method and examined under the microscope using a morphometric image-analyzer. The area and perimeter of axons were larger in the motor root than in the sensory root. The size distribution of axons was wider in the motor root than in the sensory root and the distribution pattern was unimodal type. These findings suggested that nerve fibers of the human trigeminal nerve gave similar findings to those of other peripheral nerves, regarding axonal size distribution and relative size of motor and sensory nerve axons.
\end{abstract}

The trigeminal nerve has two roots (motor and sensory) and supplies to most of the oromaxillofacial region. Its anatomical organization is very important for the analysis of such mechanisms as mastication and pain in peripheral organs (facial skin, masticatory muscles, teeth, gums). There have been many previous studies of nerves of peripheral region of the trigeminal nerves such as the ophthalmic $^{1)}$ and maxillary ${ }^{6)}$ and infra-alveolar nerves $^{5)}$, and a few report of motor ${ }^{9,12)}$ and sensory roots $^{7,9,13)}$ but they have not desultorily a comparison with motor and sensory root.

The aim of this study is, therefore to clarify the fiber component of the motor and sensory root of the trigeminal nerve and the comparison of the trigeminal nerve by morphmetrically the difference between the motor and sensory root, in few of fact that the roots are thought not to contain the autonomic nerve fibers originated from other nerve.

\section{Material and Methods}

Trigeminal nerves were obtained from 5 cadavers (males, aged from 67 to 95 years) without any disease of the central and peripheral nervous systems. The trigeminal nerve was cut near the surface of the pons and after cutting, removing the brain from the cranial cavity and we obtained the trigeminal roots with ganglion (Fig. 1). After fixation in a solution of $10 \%$ neutral formalin for 2 weeks, the specimens were transferred into a secondary fixative solution composed of $5 \%$ potassium dichromate and $5 \%$ potassium chromate $(1: 4$, in volume) and were left there for 2 weeks at room temperature and for 1 week at $37^{\circ} \mathrm{C}$. After the secondary fixation, the specimens were washed in running water overnight and dehydrated in graded series of ethanol, before embedding nitrocellulose (Shiojirin, Showa Ether Co., Tokyo, Japan). The tissue blocks were then transversely sectioned at $30 \mu \mathrm{m}$ thickness. The sections were stained by Masson-Goldner-Goto method.

For morphometry, we used an original morphometric image-analyzer comprising a light microscope was equipped with a drawing tube $(\mathrm{BH} 2$ with BH2-DA, Olympus, Tokyo, Japan), a digitizer (Crystizer a KC3300, Yokohama, Japan) and a computer (PC-9821 V13, NEC. Tokyo, Japan) running original programming software for data storing and analysis. We measured analyses of each transverse sectional area of motor and sensory

Address correspondence to: Noboru Goto, M.D., Professor and Chairman, Department of Anatomy. Showa University School of Medicine, 5-8, Hatanodai 1, Shinagawa-ku, Tokyo 142-8555, Japan 
roots as well as the area and number of nerve fiber axons of the trigeminal nerve. Enlarged images ( 70 times) were used to measure the transverse sectional area of nerve bundles excluding connective tissue. As for the analysis of nerve fibers, the systemic sampling method was employed. Five sampling sites (each $22.5 \times 22.5 \mu \mathrm{m}$ in size) were selected in each transverse section of the motor and sensory roots (Fig. 2). Highly enlarged images (3500 times with oil immersion) were used to measure the area of axons and count their number.

\section{Results}

\section{Histological Observations}

With the Masson-Goldner-Goto staining method, the axons are stained in blue and the myelin sheaths in red (Fig. 3). The trigeminal nerve is composed of several uniform fiber bundles. We counted $4-5$ in the motor root, and about 70 in the sensory root. Most of the fibers were myelinated, with only a few unmyelinated both in the motor and sensory roots.

\section{Morphometric Analysis}

The transverse sectional area of the nerves ranged from 0.176 to $0.385 \mathrm{~mm}^{2}$ (average: $0.295 \mathrm{~mm}^{2}$ ) in the motor root, and from 1.810 to $2.525 \mathrm{~mm}^{2}$ (average: $2.147 \mathrm{~mm}^{2}$ ) in the sensory root (Tables 1 and 2 ).

The area of axons in the motor root was $1.612 \mu \mathrm{m}^{2}$ to $3.040 \mu \mathrm{m}^{2}$ (average \pm SD: $2.526 \pm$ $0.565 \mu \mathrm{m}^{2}$ ), while it was $0.679 \mu \mathrm{m}^{2}$ to $1.295 \mu \mathrm{m}^{2}$ (average $\pm \mathrm{SD}: 0.896 \pm 0.250 \mu \mathrm{m}^{2}$ ) in the sensory root (Tables 1 and 2).

The perimeter of axons ranged from $4.215 \mu \mathrm{m}$ to $6.103 \mu \mathrm{m}$ (average $\pm \mathrm{SD}: 5.400 \pm 0.734 \mu \mathrm{m}$ ) in the motor root, and from $2.594 \mu \mathrm{m}$ to $3.943 \mu \mathrm{m}$ (average $\pm \mathrm{SD}: 3.078 \pm 0.533 \mu \mathrm{m}$ ) in the sensory root (Tables 1 and 2).

The total number of axons ranged from 3,486 to 6,857 (average: 5,268 ) in the motor root and from 38,042 to 69,833 (average: 51,862 ) in the sensory

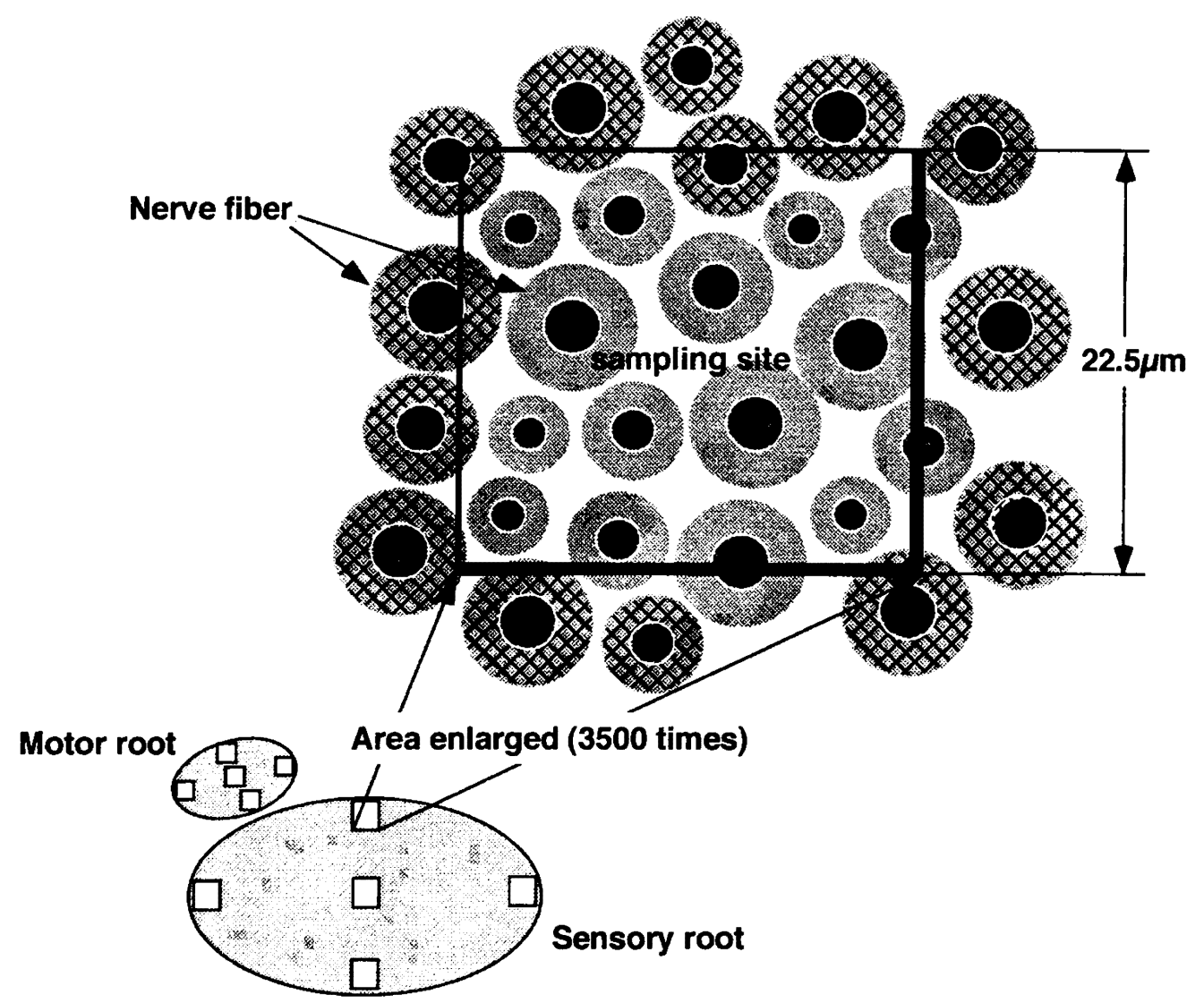

Fig. 2. Schematic drawing of systemic sampling method.

Five sampling sites were selected from each transverse section of motor and sensory roots. Highly enlarged images (3500 times) of each sampling site were used to measure axonal area and count the number of axons. Axons inside the square and on the lower and right lines (thick lines) included in the measurement; those on the upper and left lines (thin lines) were excluded. 
Table 1. Morphometric data of the motor root of the trigeminal nerve

\begin{tabular}{|c|c|c|c|c|c|c|c|c|c|}
\hline \multirow[t]{2}{*}{$\begin{array}{l}\text { Specimen } \\
\text { number }\end{array}$} & \multirow[t]{2}{*}{ Sex } & \multirow[t]{2}{*}{ Age } & \multirow{2}{*}{$\begin{array}{l}\text { Transverse } \\
\text { sectional area } \\
\text { of nerve } \\
\left(\mathrm{mm}^{2}\right)\end{array}$} & \multirow{2}{*}{$\begin{array}{l}\text { Average number } \\
\text { of axons in } \\
\text { analysis unit }\end{array}$} & \multirow[t]{2}{*}{$\begin{array}{l}\text { Total number } \\
\text { of axons }\end{array}$} & \multicolumn{2}{|c|}{$\begin{array}{l}\text { Area of axons } \\
\left(\mu \mathrm{m}^{2}\right)\end{array}$} & \multicolumn{2}{|c|}{$\begin{array}{l}\text { Perimeter of } \\
\text { axons }(\mu \mathrm{m})\end{array}$} \\
\hline & & & & & & average & SD & average & $\mathrm{SD}$ \\
\hline 1541 & Male & 67 & 0.385 & 9 & 6857 & 2.381 & 1.038 & 5.215 & 1.228 \\
\hline 1537 & Male & 72 & 0.302 & 9 & 5366 & 2.745 & 1.275 & 5.733 & 1.408 \\
\hline 1533 & Male & 89 & 0.375 & 8 & 5931 & 2.854 & 1.424 & 5.736 & 1.488 \\
\hline 1540 & Male & 90 & 0.176 & 10 & 3486 & 3.040 & 1.234 & 6.103 & 1.373 \\
\hline 1515 & Male & 95 & 0.238 & 10 & 4702 & 1.612 & 0.838 & 4.215 & 1.148 \\
\hline average & & 83 & 0.295 & 9 & 5268 & 2.526 & 0.565 & 5.400 & 0.734 \\
\hline
\end{tabular}

Table 2. Morphometric data of the sensory root of the trigeminal nerve

\begin{tabular}{|c|c|c|c|c|c|c|c|c|c|}
\hline \multirow[t]{2}{*}{$\begin{array}{l}\text { Specimen } \\
\text { number }\end{array}$} & \multirow[t]{2}{*}{ Sex } & \multirow[t]{2}{*}{ Age } & \multirow{2}{*}{$\begin{array}{l}\text { Transverse } \\
\text { sectional area } \\
\text { of nerve } \\
\left(\mathrm{mm}^{2}\right)\end{array}$} & \multirow{2}{*}{$\begin{array}{l}\text { Average number } \\
\text { of axons in } \\
\text { analysis unit }\end{array}$} & \multirow[t]{2}{*}{$\begin{array}{l}\text { Total number } \\
\text { of axons }\end{array}$} & \multicolumn{2}{|c|}{$\begin{array}{l}\text { Area of axons } \\
\left(\mu \mathrm{m}^{2}\right)\end{array}$} & \multicolumn{2}{|c|}{$\begin{array}{l}\text { Perimeter of } \\
\text { axons }(\mu \mathrm{m})\end{array}$} \\
\hline & & & & & & average & SD & average & SD \\
\hline 1541 & Male & 67 & 2.525 & 14 & 69833 & 0.982 & 0.509 & 3.204 & 0.900 \\
\hline 1537 & Male & 72 & 1.810 & 13 & 46494 & 0.785 & 0.359 & 2.887 & 0.708 \\
\hline 1533 & Male & 89 & 2.140 & 9 & 38042 & 0.739 & 0.294 & 2.761 & 0.578 \\
\hline 1540 & Male & 90 & 1.968 & 13 & 50534 & 1.295 & 0.649 & 3.943 & 1.069 \\
\hline 1515 & Male & 95 & 2.295 & 12 & 54406 & 0.679 & 0.497 & 2.594 & 0.817 \\
\hline average & & 83 & 2.147 & 12 & 51862 & 0.896 & 0.250 & 3.078 & 0.533 \\
\hline
\end{tabular}

root (Tables 1 and 2).

The distribution of axonal area was unimodal in both motor and sensory roots and, while their range was wider in the motor root than in the sensory root (Fig. 4).

\section{Discussion}

Various factors may affect the data derived from morphometric analysis, and should be taken into account. For instance, tissues may undergo deformation or shrinkage during fixation and embedding. Schwarzacher ${ }^{10)}$ reported that the human peripheral nerve might shrink by up to $40 \%$ with paraffin embedding and silver impregnation and Nakamura ${ }^{8)}$ reported similar shrinkage ratio in the case of brains with $10 \%$ formalin fixation and celloidin embedding. However, the fixation and embedding method we used ${ }^{4)}$ causes only $10 \%$. As for staining method employed, Masson-Goldner-Goto staining can distinguish the axon and the myelin sheath more easily than other methods (e.g. silver impregnation). Our choice of magnification (3500 times, instead of 1,000 times in previous studies) also helped reduce the error range, as it is generally agreed that the error range decrease in reverse ratio to the magnification. In the fact, we believe that our method may be the most suitable for morphometric analysis.

According to the traditional morphology and physiology, and previous studies ${ }^{2,3)}$, the motor nerve fiber of peripheral nerve are lager than the sensory nerve. Furthermore, Fujii and Goto $^{2)}$ and Fujii et al. $^{3)}$ reported that the size distribution of axons was wide in the facial nerve (only motor root), which is a "pure motor" nerve, and narrow in the cochlear nerve, which is a "pure sensory" nerve, while a unimodal size distribution of axon was reported both for motor (motor root of the facial nerve in Fujii and Goto ${ }^{2)}$, and the oculomotor nerve in Takeshita et al. ${ }^{11 \prime}$ ) and sensory (the cochlear nerve in Fujii et al. ${ }^{3)}$ ) nerve fiber.

Our precise finding of the human trigeminal nerve gave similar findings to there of other peripheral nerves, regarding axonal size distribution. as well as the relative size of motor nerve axons and sensory nerve axons. 


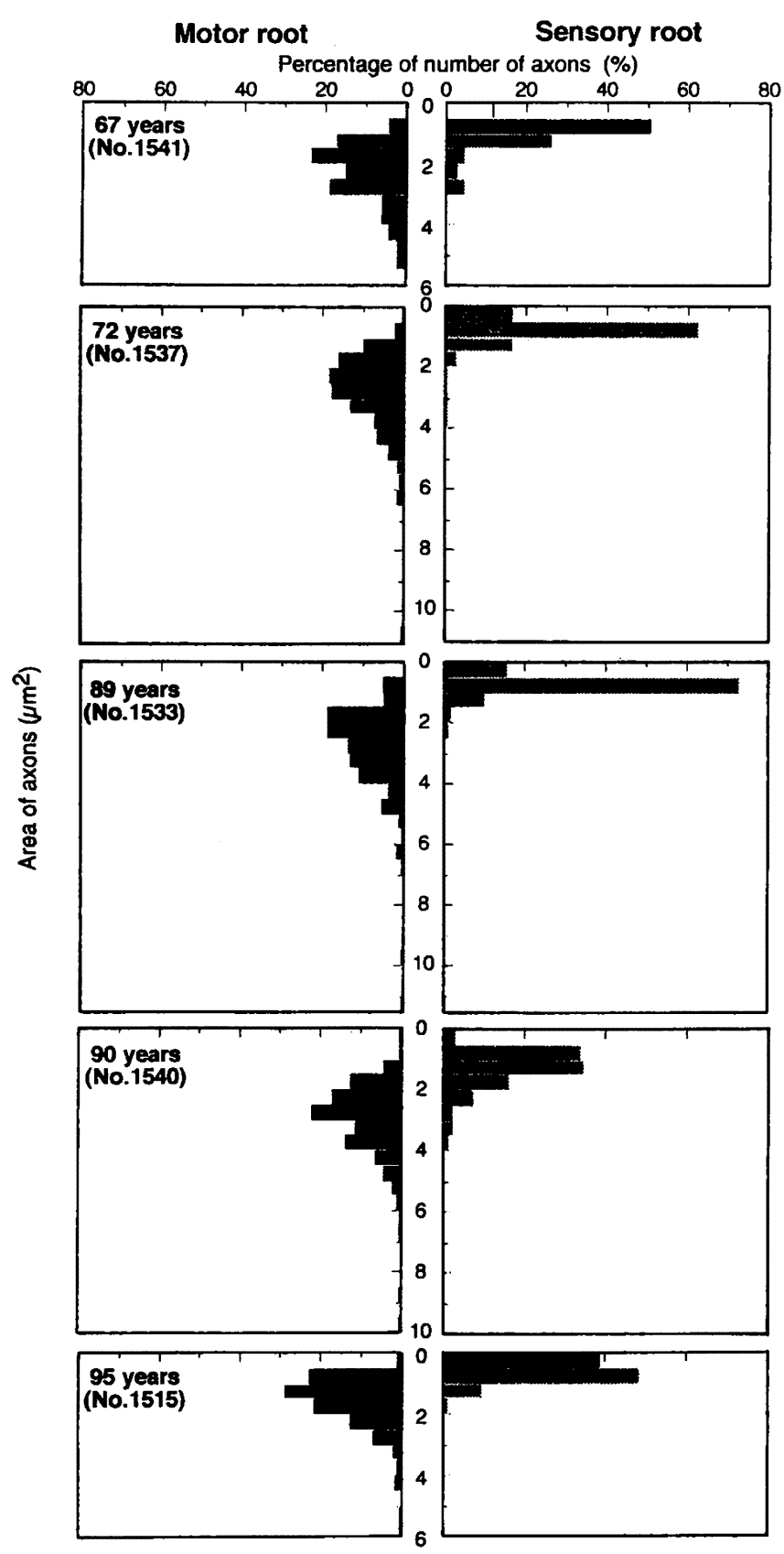

Fig. 4. Axon size distribution in the motor and sensory roots of the trigeminal nerve.

\section{Acknowledgments}

We are grateful to Mr. Masakazu Shibata (Department of Anatomy, Showa University School of Medicine) for technical advice and Dr. Akira Okada (Osaka City University) for computer programming.

\section{References}

1) Duan J, Goto N, Moriyama H, Nonaka N and LU S. Morphometric analysis of the human ophthalmic nerve and the aging process. Okajimas Folia Anat Jpn 2000; 77:87-92.

2) Fujii $M$ and Goto $N$. Nerve fiber analysis of the facial nerve. Ann Oto Rhino Laryngol 1989; 98:732-735.

3) Fujii $\mathrm{M}$, Goto $\mathrm{N}$ and Kikuchi K. Nerve fiber analysis and the aging process of the vestibulocochlear nerve. Ann Oto Rhino Laryngol 1990; 99:863-870.

4) Goto N. Discrimitive staining methods for nervous system: Luxol fast blue-periodic acid-schiff-hematoxylin triple stain subsidiary staining methods. Stain Technol 1987; 62:305315 .

5) Heasman PA. The myelinated fiber content of human inferior alveolar nerves from dentate and edentulous subjects. J Dent 1984; 12:283-286.

6) Kaneko $Y$, Duan J-H, Goto $N$ and Nagai $Y$. Nerve fiber analysis and age-related changes of the human maxillary nerves. J Showa Med Assoc 1999; 59:145-150. (in Japanese)

7) Kerr FW. Correlated light and electron microscopic observations on the normal trigeminal ganglion and sensory root in man. J Neurosurg 1967; 26 (Suppl):132-137.

8) Nakamura K. Comparative anatomy of the nerve fiber in corpus callosum and anterior commissue. Bull Kobe Med Coll 1957; 11:347-372. (in Japanese)

9) Pennisi E, Cruccu G, Manfredi M and Palladini G. Histometric study of myelinated fibers in the human trigeminal nerve. J Neurol Sci 1991; 105:22-28.

10) Schwarzacher HG. Markscheidendicke und Achsenzylinderdurchmesser in Peripheren Menshlichen Nerven. Acta Anat 1954; 21:26-46.

11) Takeshita $Y$, Matsumoto $K$, Goto $N$ and Shibata $M$. Nerve fiber analysis and aging process of the human oculomotor nerve. Showa Univ J Med Sci 1996; 8:55-61.

12) Toyoda $Y$. Analysis of the human trigeminal nerve fiber. Igaku Kenkyu 1967; 37:599-608. (in Japanese)

13) Young RF. Fiber spectrum of the trigeminal sensory root of frog, cat and man determined by electronmicroscopy. Anderson DJ, Matthews B, ed. Pain in the trigeminal region. pp. 137-47, Amsterdam, Elsevier/North-Holland, 1977.

\section{Explanation of Figures}

\section{Plate I}

Fig. 1. Macrophotograph of motor and sensory roots of the trigeminal nerve with trigeminal ganglion. M, Motor root; S, Sensory root; G, Trigeminal ganglion; Scale Bar $=10 \mathrm{~mm}$.

Fig. 3. Microphotograph of transverse sections of the trigeminal nerve. (a), Motor root; (b), Sensory root. Scale Bar $=10 \mu \mathrm{m}$. 

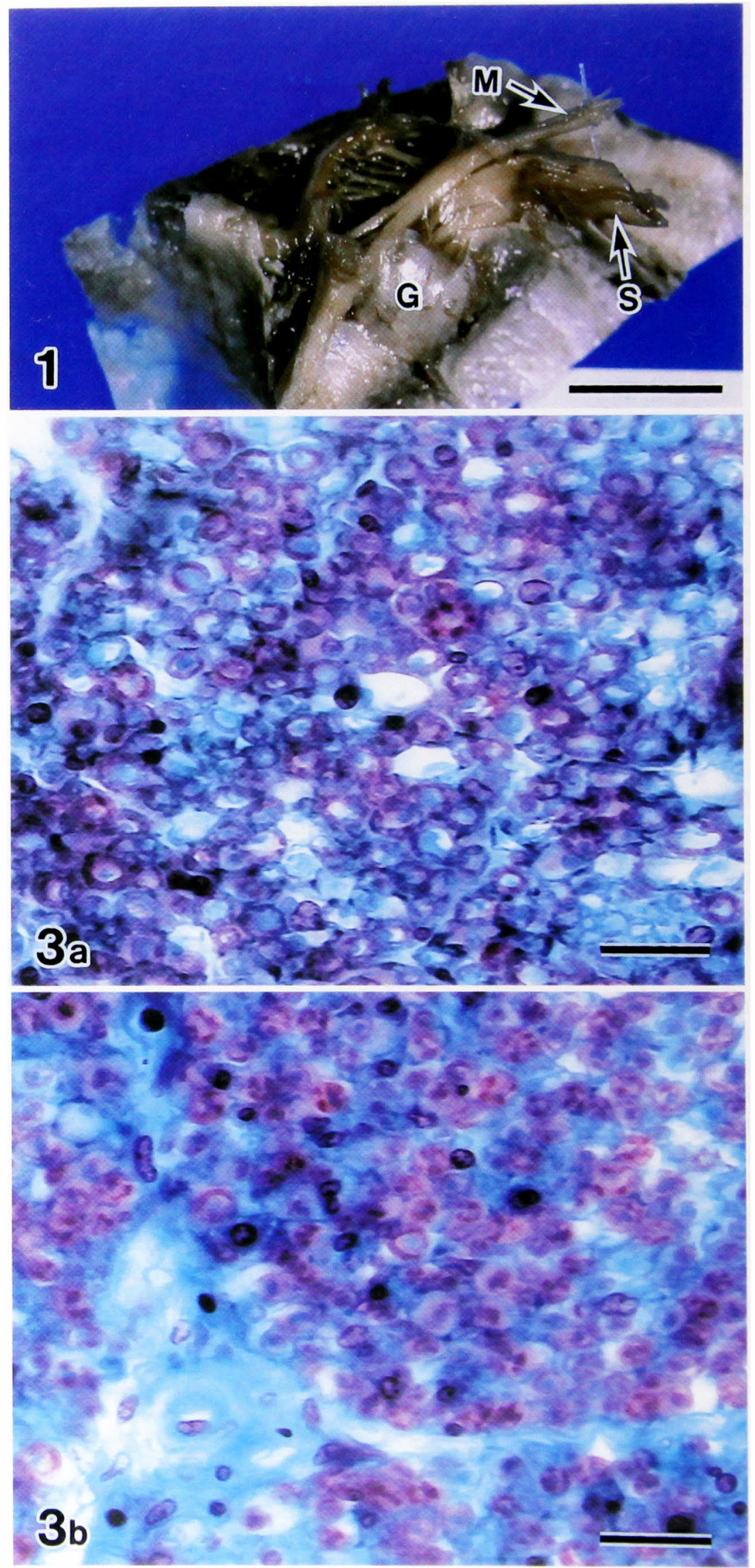